\title{
The birth of the American Physician Scientists Association — the next generation of Young Turks
}

\author{
Freddy T. Nguyen
}

Department of Chemistry, University of Illinois at Urbana-Champaign, Urbana, Illinois, USA.

\begin{abstract}
ASCI
The American Society for Clinical Investigation (ASCI) was started a century ago to foster and to address the needs of the younger physician-scientists. A hundred years later, ASCI remains one of the premier organizations for physician-scientists and one of most well-respected organizations in the medical community. I have had the opportunity and pleasure to interact with the ASCI not only as an organization through my tenure as president of the American Physician Scientists Association, but also with its members over the last four years. In my view, the same characteristics that permeate ASCI the organization also define ASCI the membership - mentorship, exemplary role models, advocacy, and leadership.
\end{abstract}

\section{The American Physician Scientists Association: the beginnings}

The American Physician Scientists Association (APSA), started over four years ago, is the only organization led by and dedicated to the physician-scientist trainee population. Since APSA's inception, the ASCI, its leadership, and members have indirectly and directly provided consistent support to APSA and its members. This is a testament to the ASCI as an organization and its members. To bring a little perspective to this piece, I think it would be prudent to provide some background. As an MD/PhD student, I founded APSA as an organization devoted to addressing the needs of physician-scientist trainees along with three other MD/ $\mathrm{PhD}$ students. APSA was formed during a time when there was a growing concern within the academic medicine community about the decline of physician-scientists being actively voiced by many, including former and future ASCI presidents, such as Joseph Goldstein, Timothy Ley, Ajit Varki, and Nancy Andrews, to name a few (1-7). Of equal concern was the lack of a national forum for physician-scientist trainees to meet, provide peer mentoring, discuss their research, identify career options, and address training issues across institutions. These initial concerns laid the groundwork for APSA as a national organization dedicated to the career development and community building of physician-scientist trainees. During the formative days of APSA, ASCI member Lawrence Brass first directed us to the Society's interest in fostering and supporting the training and careers of future physician-scientists, leading me to make contact with Kenneth Kaushansky and Leonard Zon, the outgoing and incoming ASCI presidents at the time, who both pledged initial support to the fledging APSA.

\section{APSA and ASCI: the organizations}

In light of the fact that ASCI was started a century ago, the similarities between the beginnings of the ASCI and the beginnings of the APSA are remarkable. Likewise, the differences are of equal interest, as they highlight the true need that these organizations have fulfilled in their respective times. While recently perusing the early history of the ASCI by Ellen Brainard (8), I was continually reminded of APSA's beginnings. By observing the parallels between the two organizations, I have come to realize how ASCI's

Conflict of interest: The author has declared that no conflict of interest exists. Citation for this article: J. Clin. Invest. 118:1237-1240 (2008). doi:10.1172/JCI35193. history could serve as a roadmap for how APSA could be built and organized. ASCI was started during a time when medical research institutions were first established and the idea of a physician-scientist who was more dedicated to a full-time career in research and education than to private practice was just evolving. APSA, on the other hand, was founded during a time when the future of the physician-scientists workforce was uncertain. Both were targeted at helping support the younger members of the physician-scientist community and helping them stay committed to a career as a physician-scientist. The ASCI's first president, Samuel Meltzer, spoke of reclaiming the "brainy young men" who had been lost to the allied sciences, whereas today we must reclaim the bright young minds that are being lost to private practice (8).

The ASCI, through its affiliations with larger federations, has helped advocate for issues directly affecting physician-scientists, such as the establishment of the NIH Loan Repayment Programs to support young physician-scientists and scientists committed to a career of medical research (3). The ASCI's affiliation with groups such as the Federation of American Societies for Experimental Biology (FASEB) exemplifies its role as a collaborative organization working with other stakeholders on common goals to further support the careers of physician-scientists. While at the 2007 APSA New York Physician Scientists Symposium, I was able to briefly hear from Harold Varmus and Charles Sawyers (the current ASCI president) about the ASCI's involvement with the Coalition for the Life Sciences, whose goal is to "foster public policies that advance basic biological research and its applications in medicine," and the need for physician-scientists and scientists to be more vocal and active in the political process (9). The issues addressed through this coalition range from science education to professional training to the funding of medical research. This is reminiscent of Tim Ley's presidential address, in which he advocated for the ASCI to join FASEB and to develop an advocacy component (10). APSA was formed with a similar collaborative spirit, working closely with medical, scientific, and physician-scientist organizations on both the student level and the professional level and focusing on projects or issues directly relevant to the recruitment and retention of physician-scientist trainees.

Although ASCI is an elected membership, the Society speaks and works on behalf of the physician-scientist community (10). The ASCI led the academic medicine community by setting an example when it became one of the first societies to commit to having a 


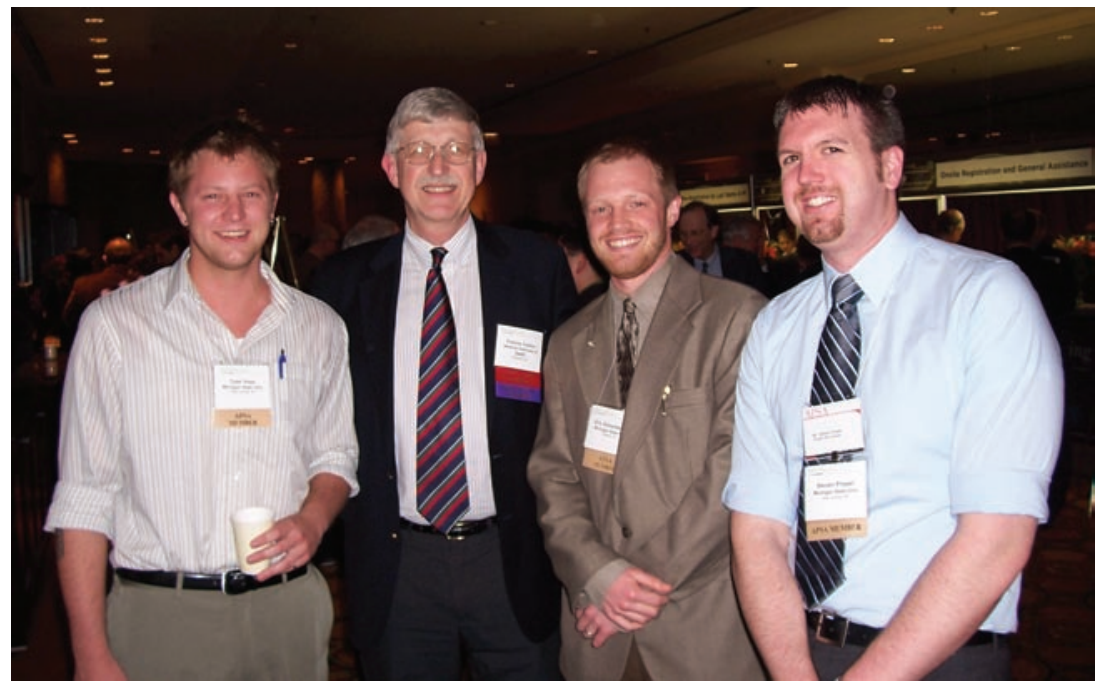

Figure 1

APSA members meet with Francis Collins during the 2007 Annual Meeting. Left to right: Tyler Voss, Francis Collins, Eric Schauberger, and Steven Proper.

free-access journal. Since 1996, The Journal of Clinical Investigation has been published freely online with unrestricted access, during a time when many societies and publishing groups were still in heated debates over issues such as copyrights, public access, and the financial burden of publishing (11). APSA, with a membership of more than 1,000 and formal representation in over 115 medical institutions, works on behalf of all physician-scientist trainees. One of APSA's long-standing commitments has been to give trainees easy and open access to resources and services such as the electronic resources developed by APSA and the mentoring networks facilitated through our annual and regional meetings.

\section{The Annual Meeting}

As momentum among physician-scientist trainees continued to grow, the goals and missions of the organization soon began to take shape in 2004. The conversations with Len Zon progressed through the summer as he provided his personal guidance and pledged the ASCI's support, leading to the establishment of the APSA Annual Meeting and its alignment with the ASCI/AAP Joint Meeting. As simply as that, the APSA Inaugural Annual Meeting was born. While the Joint Meeting focused on high-caliber scientific presentations of cutting-edge medical research from worldrenowned speakers, APSA provided career-oriented talks from leading physician-scientists in addition to a career panel providing trainees with insights on how to successfully navigate the physician-scientist training path and the early career stages.

In each subsequent year, the relationship between the APSA Annual Meeting and the ASCI/AAP Joint Meeting grew more intimate as the meeting moved to the Fairmont Chicago hotel in its second year, allowing more opportunities to integrate APSA events throughout the length of the Joint Meeting (Figures 1-3). APSA has helped further realize the ASCI's goal to foster and mentor the next generation of physician-scientists by expanding the attendance of trainees at the ASCI/AAP Joint Meeting. While the ASCI reached out to $\mathrm{K}$ grant awardees, APSA brought medical student trainees who were mostly $\mathrm{MD} / \mathrm{PhD}$ students but included tradi- tional medical students in research-intensive training programs, PhDs pursuing their medical degrees, and DO/PhD students. These recruiting efforts combined with the attendance of ASCI and AAP members have resulted in the only national and international conference that brings together the full gamut of the physician-scientist pipeline under one roof, from the medical student trainee to the K08 awardee to the young physician-scientist (ASCI members) to the established physician-scientist (AAP members).

The 2005 meeting left a lasting impression, since it crystallized the primary objective of the ASCI and AAP by bringing together Nobel laureates Michael Brown, Joseph Goldstein, Peter Agre, Sidney Brenner, Stanley Prusiner, and Philip Sharp and NIH director Elias Zerhouni as its speakers. The caliber of the research presented and the speakers continues to excel at ASCI meetings to this day, addressing the latest research topics in medicine and inspiring current and future physician-scientists alike. APSA members continue to be attracted to the speaker lineup year after year and also to the ASCI and AAP members in attendance. As honor societies for physician-scientists, they are the cream of the crop and represent a cadre of physician-scientists who have excelled in their research endeavors and become leaders at their respective institutions, and yet continue to have a sincere interest in mentoring and supporting the next generation of physician-scientists.

Perhaps one of the most memorable parts of the meeting is the ASCI presidential address, which has evolved considerably from the initial scientific talks given by the first presidents. From President Barbara Weber's emotional speech given last year to Ajit Varki's futuristic report (from the year 2049) (12) on the status of physician-scientists, the presidential addresses have focused on the moving issues facing physician-scientists, calling on their fellow members to help lead and define the physician-scientist community $(5,10,13-15)$. These addresses have focused on topics such as the future of physician-scientists, defining clinical investigation, research funding, medical/scientific education, and mentoring, defining the ASCI's role in addressing the needs of the Society and the physician-scientist community (13). 


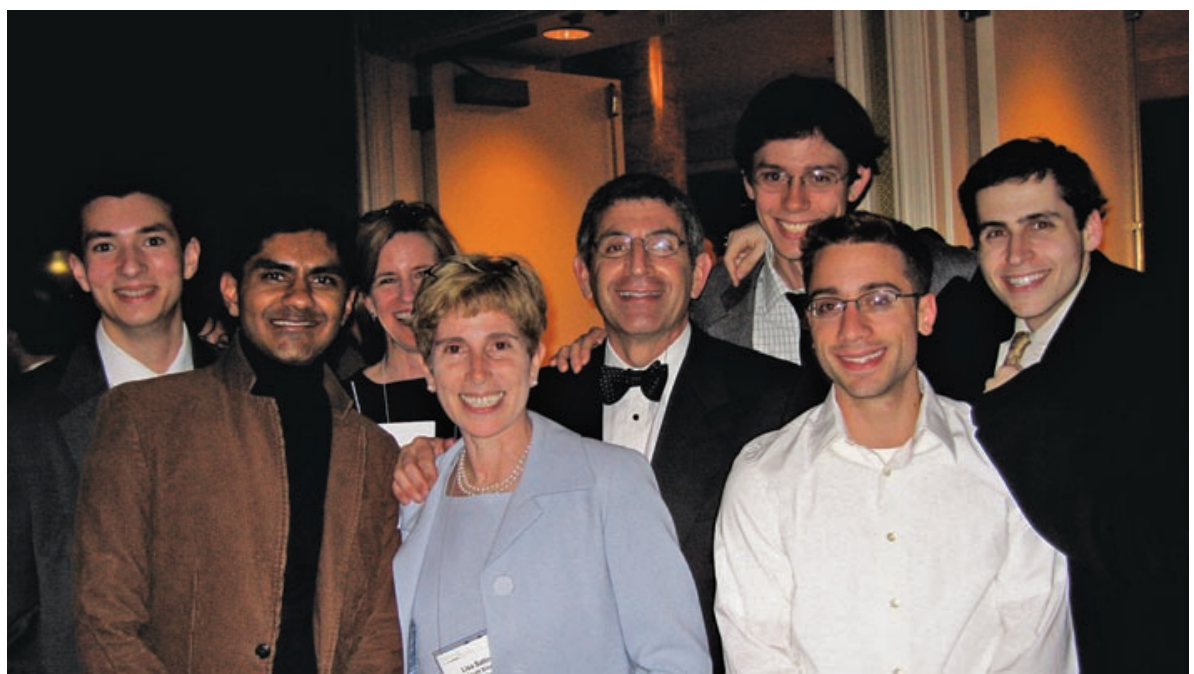

Figure 2

APSA members with ASCI members Lisa Satlin and Paul Klotman at the 2007 Annual Meeting. Front row, left to right: Vivek Rudrapatna, Lisa Satlin, and Michael Green. Back row: Jameel Iqbal, Mary Klotman, Paul Klotman, Thomas Hays, and David Braun.

\section{ASCl: the members beyond the organization}

Thus far, I have mostly focused on the direct contributions of the ASCI as an organization and the contributions its members have made under the umbrella of the ASCI. However, ASCI members have individually had far-reaching influence within the field of medicine that extends beyond their traditional roles and into the policy and advocacy arenas. Their collective contributions to mentoring and supporting the next generation of physician-scientists permeates all facets of their careers, whether through their teaching, their leadership roles in organizations and societies, or their leadership roles at their home institutions.

As the APSA president, I have had the great opportunity and pleasure to interact with many of these individuals. One of the organizations that APSA has recently begun to interact with to help address issues relating specifically to the training of $\mathrm{MD} / \mathrm{PhD}$ students is the National Association of MD/PhD Programs. Recently our two organizations have opened up lines of communications, allowing for a free exchange of information with regard to our respective goals and projects; this was initiated by Lawrence Brass, the president at the time and an ASCI member, who asked me to address the group at their 2007 meeting. To make the conversation truly bidirectional, APSA proceeded to invite David Engman, president elect of the group and a recent inductee into the ASCI, to speak to the governing body of APSA during our 2007 meeting. Since these initial interactions, both groups have been sharing insights on various issues, such as the recruitment, retention, and training of $\mathrm{MD} / \mathrm{PhD}$ students.

Similarly, when the Association of Professors of Medicine (APM) launched their PhysicianScientist Initiative in 2006, Andrew Schafer, the lead PI and former ASCI secretary-treasurer, invited me to become involved with the initia- tive, providing a voice to the current trainee population on the planning committee. This initiative is taking a comprehensive approach to "identify, develop, and implement substantive and practical solutions that will ensure the survival, growth, and diversity of the physician-scientist workforce" (16). Nearly two-thirds of the committee are ASCI members, including several familiar faces, such as Nancy Andrews (ASCI president elect), William F. Crowley Jr. (a keynote speaker at the APSA Inaugural Meeting), Joe G.N. Garcia (a panelist on this year's APSA Career Panel), Kenneth Kaushansky (past ASCI president), and Paul Rothman (a regular participant in the APSA Residency Luncheon). These individuals exemplify the impact of ASCI members in supporting and advocating for the training of physician-scientists.

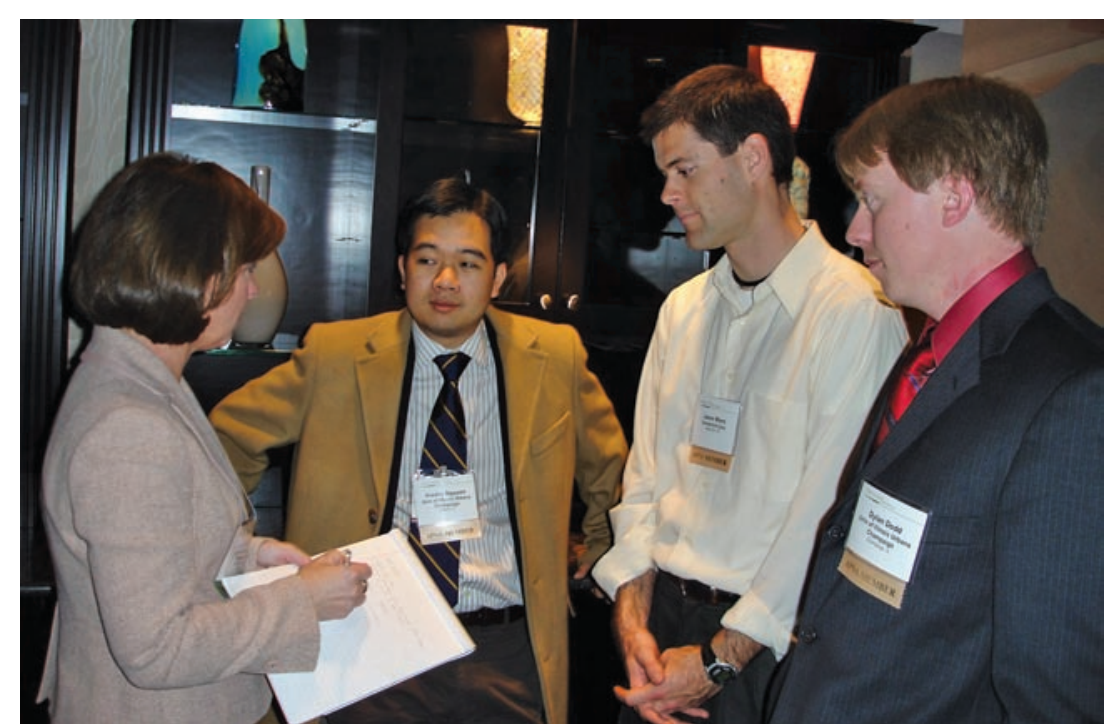

Figure 3

APSA leaders meet with Lori Ennis, executive director of the AAP, to discuss the future directions of APSA. Left to right: Lori Ennis, Freddy Nguyen, Jason Mann, and Dylan Dodd. 


\section{What do the present and future hold for physician- scientists and the organizations that represent them?}

This is the age-old question that the ASCI and other organizations have attempted to answer over the years. I would certainly be remiss not to acknowledge the many ASCI presidents, among many others, who have tried to predict the future of physician-scientists by looking through their crystal ball. According to David Ginsburg's 2002 ASCI presidential address, over half of the previous addresses have focused on the fate of physician-scientists or on the state of the ASCI (13). However, I certainly share Ginsburg's optimistic attitude in believing that the physician-scientist, although still considered an endangered species by many, has a bright future as opportunities continue to increase while we move away from the traditional definitions and roles of the physician-scientist. With the ASCI as a model providing inspiration to APSA - the newest organization of Young Turks - we look ahead to the next 100 years.

Since the inception of APSA, we have been able to positively impact the landscape for physician-scientist trainees by creating a national network enabling us to provide horizontal and vertical mentoring and networking opportunities in coordination with organizations such as the ASCI and AAP through our annual and regional meetings. Similar to the mentoring trainees are receiving from senior trainees and current physician-scientists, APSA is using its regional meetings to propagate the mentoring down to undergraduates and others cultivating their research interests and supporting them in the career path. This outreach moved beyond the undergraduate level last summer to high school students when APSA piloted a program in which our institutional representatives spoke on physician-scientist careers and training.

By instilling the value of mentoring both on the receiving and giving ends, APSA hopes to prepare physician-scientist trainees to become and to continue to be good mentors as they progress through their careers as physician-scientists. By addressing the career and training issues facing up-and-coming physician-scientists, we have brought more educational awareness to current trainees. The earlier our trainees are involved in fostering the next generation of physician-scientist trainees, the more likely they will be to take on those issues as they rise through the ranks of academic medicine. Likewise, we are reaching out to traditional medical students in an effort to engage them in medical research and to help them cultivate an appreciation for the medical research enterprise. These efforts should help contribute to a culture change in the recruitment, retention, and promotion of future physician-scientists.

The multiple leadership opportunities within APSA will further develop the leadership skills and interests of our members, who we hope will contribute to the physician-scientists community, medicine, and science in the many ways that ASCI leaders and members have over the years. With successful physician-scientist leaders addressing our members during the annual and regional meetings, we are providing our members access to exemplary role models who are inspiring the physician-scientists of tomorrow today. A recent APSA initiative assessing the opinions and perceptions of medical students is looking to identify the reasons trainees choose to or not to pursue a physician-scientist career and potential issues impacting their training and career expectations as physician-scientists. This type of activity brings about more awareness about the advocacy and policy roles we must play as physician-scientist trainees.
With regard to the preservation of the physician-scientists population, organizations such as APSA, ASCI, and many others have always been taking active and leading roles on this issue. However, no single organization can take on this burden alone. Comprehensive and collaborative initiatives such as the one initiated by the APM are the best ways to move forward. Stakeholders of the physician-scientist community should come together to share information, coordinate initiatives, and support each other in their respective efforts. Every entity has its own unique strengths to bring to the table, and only by working together will we be able to have a true positive impact. Let us use the phrase Young Turks, which has come to be closely associated with the ASCI, to redefine the physician-scientist community as one that constantly strives to innovate or, as some would say, to rebel against the status quo.

Interestingly enough, the emergence of physician-scientist trainee organizations and of $\mathrm{MD} / \mathrm{PhD}$ training programs at the global level has only recently occurred. With the ideas of APSA first brewing in late 2003, the Swiss MD/PhD Association and the Clinician Investigator Trainee Association of Canada were founded in 2003 and 2006 , respectively. Formal MD/PhD programs now exist in Canada, Switzerland, the United Kingdom, France, Germany, Israel, and several other countries. The international landscape for training physician-scientists will certainly change in the upcoming years as other countries allocate more funding toward medical research and the training of physician-scientists. With these new developments, it is crucial for us to maintain our expertise in training physician-scientists and continue to fund, support, mentor, and create innovative training pathways for physician-scientists.

Address correspondence to: Freddy T. Nguyen, Department of Chemistry, College of Medicine, Beckman Institute for Advanced Science and Technology, University of Illinois at Urbana-Champaign, 405 North Mathews Avenue, Urbana, Illinois 61801, USA. Phone: (312) 285-0485; Fax: (217) 344-1986; E-mail: fnguyen@ physicianscientists.org.

1. Andrews, N.C. 2002. The other physician-scientist problem: where have all the young girls gone? Nat. Med. 8:439-441.

2. Goldstein, J.L., and Brown, M.S. 1997. The clinical investigator: bewitched, bothered, and bewildered - but still beloved. J. Clin. Invest. 99:2803-2812.

3. Ley, T.J., and Rosenberg, L.E. 2002. Removing career obstacles for young physician-scientists - loan-repayment programs. N. Engl. J. Med. 346:368-372.

4. Ley, T.J., and Rosenberg, L.E. 2005. The physician-scientist career pipeline in 2005: build it, and they will come. JAMA. 294:1343-1351.

5. Varki, A. 1999. Executive summary of the Nerflex Commission Report. J. Clin. Invest. 104(Suppl.):S1-S3.

6. Varki, A., and Rosenberg, L.E. 2002. Emerging opportunities and career paths for the young physician-scientist. Nat. Med. 8:437-439.

7. Zemlo, T.R., Garrison, H.H., Partridge, N.C., and Ley, T.J. 2000. The physician-scientist: career issues and challenges at the year 2000. FASEBJ. 14:221-230.

8. Brainard, E.R. 1959. History of the American Society for Clinical Investigation, 1909-1959. J. Clin. Invest. 38:1784-1864.

9. The Coalition for the Life Sciences (formerly The Joint Steering Committee for Public Policy). http://www.jscpp.org/.

10. Ley, T.J. 2003. 1998 ASCI Presidential Address. J. Clin. Invest. 112:S9-S11.

11. Hawley, J.B. 2003. The JCI's commitment to excellence - and free access. J. Clin. Invest. 112:968-969.

12. Varki, A. 1999. Executive summary of the Nerflex Commission Report. J. Clin. Invest. 104:S1-S10.

13. Ginsburg, D. 2002. The history and evolution of the ASCI: deja vu all over again. J. Clin. Invest. 110:S1-S4.

14. Koretzky, G.A. 2001. The future of the ASCI (American Society for Clinical Investigation): a lesson from 2000 presidential election. J. Clin. Invest. 108:S3-S7.

15. Weber, B.L. 2007. In the palace of the sultan: 2007 American Society for Clinical Investigation Presidential Address. J. Clin. Invest. 117:1727-1731.

16. Haupt, A. 2007. APM spearheads Physician-Scientist Initiative. Academic Internal Medicine Insight. 5:12-13 